\title{
EFFECTS OF WASTE CERAMIC DUST AND BUTYL RUBBER ON RHEOLOGICAL PROPERTIES OF ASPHALT BINDER
}

\author{
Sagni Temesgen Olkeba ${ }^{1}$ and Avinash Mahdevro Potdar ${ }^{2}$ \\ Department of Civil Engineering, College of Architecture and Civil Engineering, University of Addis Ababa \\ Science and Technology, Addis Ababa, Ethiopia, Tel: $+251915877503^{1},+251929397050^{2}$, e-mail: \\ saniolkeba@gmail.com
}

Received Date: April 23, 2020; Revised Date: August 4, 2020; Acceptance Date: November 10, 2020

\begin{abstract}
This study was carried out using different methods to assess the contribution of asphalt mastic to the performance of a pavement at high temperature in rut resistance when waste ceramic and butyl rubber powders blended within the bitumen. In this research bitumen 80/100 modified at different percentages $(0 \%, 1 \%, 2 \%$, and $3 \%)$ of Ceramic-Butyl Rubber (CBR) by weight of neat bitumen were studied. Firstly, the asphalt mastic samples were prepared by mixing in a laboratory at an average temperature of $180^{\circ} \mathrm{C}$ for about 60 minutes with mixer operated at $800 \mathrm{rpm}$. Next, in this regard, a different experimental program such as conventional tests and super pave tests were conducted. The conventional test results show that modified bitumen has decreased penetration value, increased softening point and lower ductility value. This indicates that, with the addition of CBR modifiers, the softness of the bitumen drops seriously. Additionally, the complex modulus of master curves results illustrates that the addition of CBR modifiers can enhance the rutting resistance of softer binder at high temperature and low frequency. Moreover, the rutting parameter $\mathrm{G}^{*} / \sin (\boldsymbol{\delta})$ results were increased from $\mathrm{PG} 64^{\circ} \mathrm{C}$ to $70^{\circ} \mathrm{C}$ with increasing of CBR from $2 \%$ to $3 \%$ respectively, while they are declined significantly with increased temperatures. This improvement shows that CBRs modified bitumen may be suitable for using in hot climates to develop stiff flexible asphalt mixtures. Finally, the MSCR test results illustrates that the CBR dramatically increases the resistance of bitumen to rutting by reducing the Jnr and increasing the recovery percent of bitumen.
\end{abstract}

Keywords: Asphalt mastic, Durability, Inorganic polymers, Recycling, Stiffness

\section{Introduction}

To improve the quality life of flexible pavement and environmental issues, the civil engineers and researchers are currently used different methods to characterize bitumen and are utilized the industrial waste materials as modifiers has become attractive options in recent times[1, 2]. Bitumen is always become our first choice to use in paving that easily affected by variation in temperature, traffic loading, and duration of loading. However, rutting is more significant with combined effect of high temperature and heavy traffic loading with slow moving truck that leads the pavement to high reconstruction cost and great economic losses [3, 4]. The non-polymer additives (fillers) closely associated in asphalt mixtures with a dual role such as; they serve as to fill the voids between coarse and fine aggregate particles while altogether bitumen mixes with fillers indicate bituminous mastic [5].

In the current researches, an appropriate polymers and non-polymers, reactive modifications are introduced to reduce risk of permanent deformation [6-10]. The investigations from different studies suggested that asphalt mastic has highly coated 
aggregate than virgin coated aggregate [11] with very often advantages, which are; it improves stiffness of the bitumen by dispersed in it [12] and holds aggregate ingredients together for improvement of stripping [13].

In previous studies, ceramics are used as a thermal insulator materials effect on pavement temperature variation $[14,15]$ because of most of pavement distress such as permanent deformation, fatigue cracking and low thermal cracking are highly related to temperature variations. The authors in [16] used ceramic powder and hydrate lime filler in semi-dense bituminous concrete by Marshall mix design. The characterization studies reported that ceramic dust improves the stability and environmental issues than hydrate lime. Although, an asphalt modified with ceramic fiber were characterized and investigated by [17] using Dynamic Shear Rheometer (DSR) with different percent of modifiers (1\%, $2 \%$, and $3 \%$ ) by weight of bitumen. The assessment shows that ceramic fiber composed of $\mathrm{SiO}_{2}, \mathrm{Al}_{2} \mathrm{O}_{3}$ improves stability at high temperature for rutting resistance and temperature sensitivity of binder when the temperature drops between $30^{\circ} \mathrm{C}$ and $50^{\circ} \mathrm{C}$.

The behaviors of mortar containing ceramic powder as replace cement were studied by [18], at different ratio of (0\%-60\% with $20 \%$ increments) using X-ray diffraction and Field Emission Scanning Electron Micrograph. The results shown that, $40 \%$ of ceramic dust replace of cement improves compressive strength, improved microstructure and mortar strength properties. In [14] the effect of thermal conductivity of ceramic materials as aggregate ingredients on pavement temperature were examined by Finite Element Model using percent of $(0 \%-80 \%$ by $20 \%$ increment $)$. The result concluded that replacement of less than $40 \%$ of ceramic aggregate to natural aggregate reduces thermal conductivity which proven reducing the temperature gradient of pavement.

As well as butyl rubber is used in this study to make sense for the solution of pollution, a cleaner, safer environment, and safer roads with excellent adhesion [10, 19], sound absorption (noise reduction by self-lubrication, improved elastic deform and recovery properties [6]. According to the study of [19] styrene-butyl acrylate (SBA) improved that the Reclaimed Asphalt Pavement using styrene-butyl acrylate (SBA) polymer with $2 \%, 4 \%$, and $6 \%$ by weight of extracted asphalt. The result revealed that extracted asphalt modified with $4 \%$ of SBA improves HMA in high stability, and gave long service life.

Although, The investigation of [20] proved that, the rheological properties of Styrene-Butadiene-Rubber (SBR) and Natural Rubber (NR) polymer-modified emulsions bitumen at average pavement temperature to correlate the behavior of both polymers in linear viscoelastic range and non- linear viscoelastic range with $0 \%, 3 \%, 4 \%$, and 5\% percent by mass of binder. The result of the finding shows that NR improves the asphalt stiffness and elastic properties to resist permanent deformation in both regions; while only Styrene Butadiene Rubber was highly sensitive to stresses in Non-Linear Visco-Elastic regions.

The motive of the study work is to improve the rheological behavior of bitumen performance and temperature susceptibility enhancement observed in polymers. The aim of the research is to study the contribution of the produced asphalt mastic using different percentage of modifiers in resistance to permanent deformation at high temperature using super pave test. The recycled use of industrial wastes is not solely addressing the engineering properties of asphalt binder in flexible pavement but also environmental solution for pollution. Considering these difficulties in this paper utilized environmental friendly industrial waste materials used as an innovation options in the technology of asphalt modification to characterize the rheological properties of asphalt binder. 


\section{Materials and Methodology}

\section{Material Properties and Sample Preparation}

An unmodified 80/100 pen grade of bitumen and two modifiers such as waste ceramic dust and waste butyl rubber powder were used in the experiment. This bitumen were used as per the recommendations from [21], because of softer consistency, not suitable for hot climatic condition under heavy traffic loading. The physical properties for both neat and modified bitumen was listed in Table 1 [21-24]. Both modifiers samples were obtained from disposal of waste solid materials, collected manually, cleaned, dried, broken into smaller size, crushed and/or grinded into desired size, sieved by No\#200 sieves and finally the required size less than $75 \mu \mathrm{m}$ was collected and prepared as a modifiers as shown in Figure 1 and 2. Their chemical properties were also presented in Table 2.

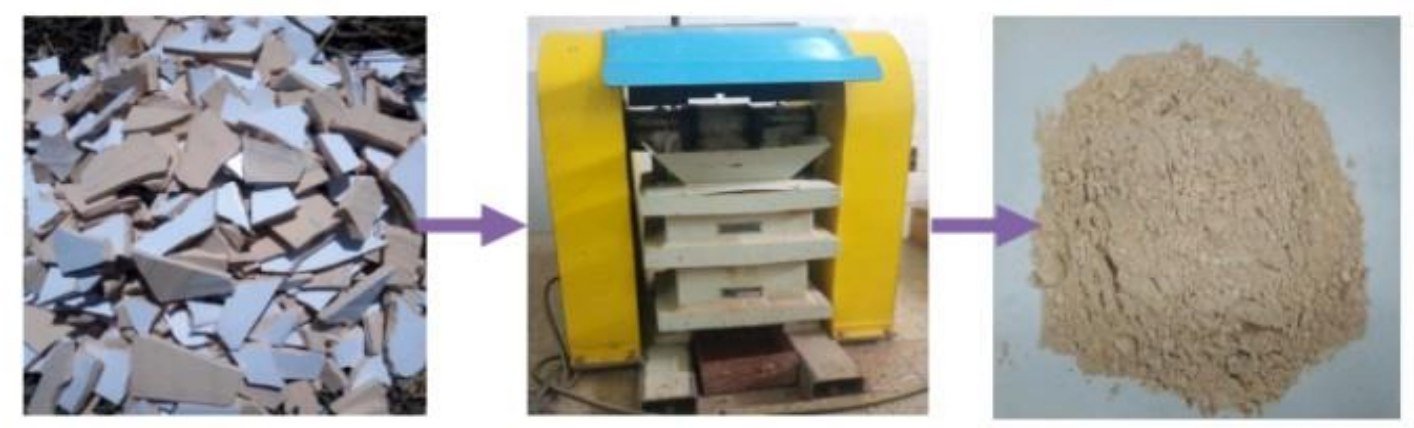

Figure 1. Sampling for waste ceramic materials

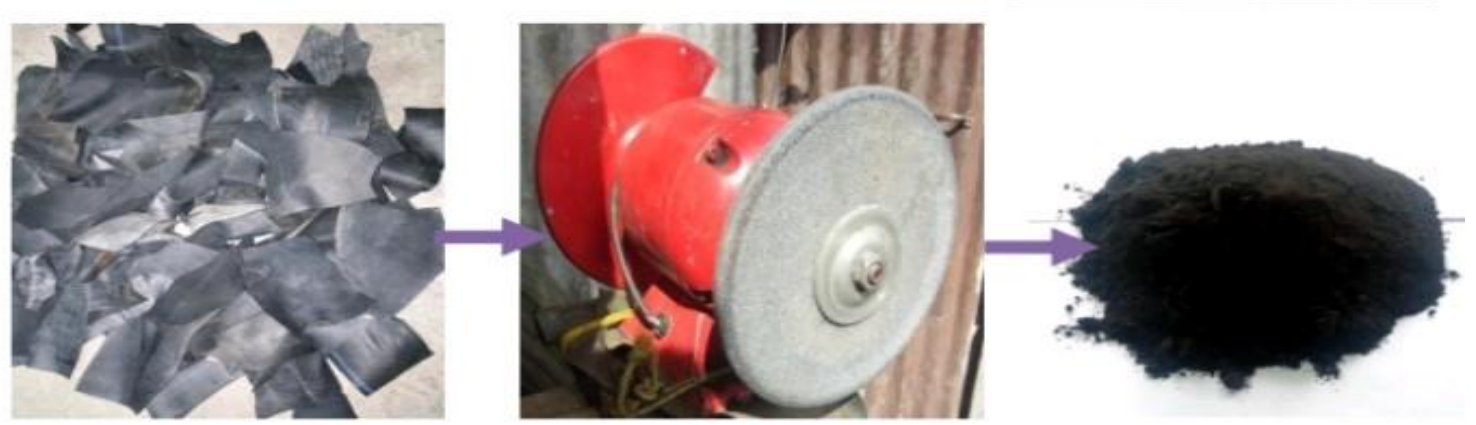

Figure 2. Sampling for waste butyl rubber

Table 1. The Physical Properties of 80/100 Bitumen

\begin{tabular}{|c|c|c|c|c|c|c|c|}
\hline Test Type & Method & $\begin{array}{c}\text { Specificatio } \\
n\end{array}$ & & $\begin{array}{c}0 \% \\
\text { (neat) }\end{array}$ & $\begin{array}{l}1 \% \text { wgt } \\
\text { of CBR }\end{array}$ & $\begin{array}{l}2 \% \text { wgt } \\
\text { of CBR }\end{array}$ & $\begin{array}{l}3 \% \mathrm{wgt} \\
\text { of CBR }\end{array}$ \\
\hline Penetration, $25^{\circ} \mathrm{C}$ & ASTM-D5 & $80-100$ & & 96 & 83 & 76 & 69 \\
\hline Ductility at $25^{\circ} \mathrm{C}$ & ASTM-D113 & 100 (min) & & $100+$ & 65 & 48 & 41 \\
\hline Softening point ${ }^{\circ} \mathrm{C}$ & ASTM-D36 & $42-51$ & & 47 & 54 & 62.7 & 66.2 \\
\hline Loss by mass (\%) & $\begin{array}{l}\text { ASTM- } \\
\text { D2872 }\end{array}$ & $0.8(\max )$ & Aged & $0.05 \%$ & & & \\
\hline
\end{tabular}


Table 2. The Chemical Properties of Modifiers

\begin{tabular}{lll}
\hline Chemical Compound (\%) & Butyl Rubber Powder & Ceramic Powder \\
\hline $\mathrm{SiO}_{2}$ & 13.88 & 65.84 \\
$\mathrm{Al}_{2} \mathrm{O}_{3}$ & 4.63 & 24.08 \\
$\mathrm{Fe}_{2} \mathrm{O}_{3}$ & 3.80 & 1.40 \\
$\mathrm{CaO}$ & 2.72 & 6.72 \\
$\mathrm{MgO}$ & 1.02 & 0.62 \\
$\mathrm{Na}_{2} \mathrm{O}$ & 0.32 & 0.72 \\
$\mathrm{~K}_{2} \mathrm{O}$ & $<0.01$ & $<0.01$ \\
$\mathrm{MnO}_{2}$ & 0.06 & 0.04 \\
$\mathbf{P}_{2} \mathrm{O}_{5}$ & 0.12 & 0.13 \\
$\mathrm{TiO}_{2}$ & 0.04 & 0.18 \\
$\mathrm{H}_{2} \mathrm{O}$ & 1.54 & 0.15 \\
\hline
\end{tabular}

\section{Asphalt Mastic Preparation Methods}

Altogether, bitumen mixes with fillers indicate bituminous mastic. The bitumen 80/100 penetration grade was used in this study. The modifiers were used in powder forms which were pre-treated and labeled as Ceramic-Butyl Rubber (CBR) in laboratory. Then, CBR powders were dried at $150^{\circ} \mathrm{C}$ for $24 \mathrm{hr}$ before added to the bitumen to remove free moisture. For the assessments based on previous studies [16], the amount of ceramic dust and butyl rubber together with the same proportion were prepared with $1 \%, 2 \%$ and $3 \%$ by weight of binder to compare with neat binder. The basic processes used to add polymer into bitumen are wet method (addition of solid polymers into asphalt) and dry method (addition of solid polymer into hot mix asphalt or directly to aggregates) [25].

In this research, wet method was used to mixes solid polymer (ceramic and butyl rubber dusts) with asphalt binder in high temperature than the bitumen will be used into the mix. Mixing time and mixing temperature depend on the type of polymer and bitumen. For example [26], investigated and analysis of digestion time and the crumb rubber percentage in dry-process crumb rubber modified hot bituminous mixes. The report suggests that a crumb rubber percentage of less than $1 \%$ of the total weight of the mix and a digestion time of 90 min produced the best results. Based this mixing time 60 minutes were selected in this study.

The bitumen was heated and the mixing temperature was $175-185^{\circ} \mathrm{C}$ with mixer operated at $800 \mathrm{rpm}$. Once the average target temperature was reached in the given range, modifiers were slowly added into the bitumen and mixing were continued for about $60 \mathrm{~min}$ because of the mixing time should be adequate enough for homogeneous dispersion of the solid particles within the bitumen matrix. Temperature controlling during mixing achieved by thermometer (see Figure 3). After mixing, completed a total of three asphalt mastic (1\% $\mathrm{CBR}, 2 \% \mathrm{CBR}$ and 3\% CBR) were designed and removed from the asphalt sample container, divided to other container for Rolling Thin Film Oven (RTFO) test in accordance to [23]. 


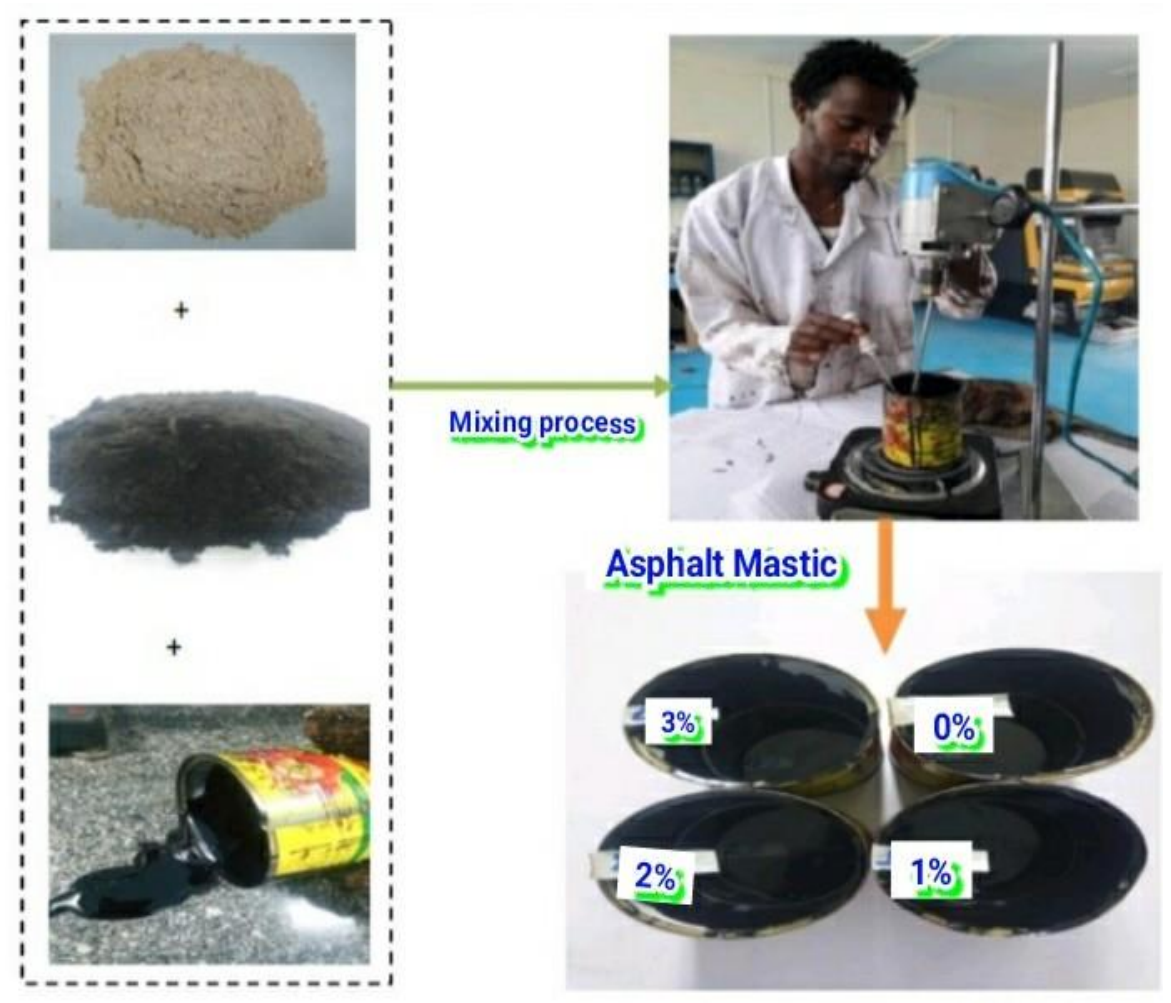

Figure 3. Asphalt mastic preparation methods

\section{Test program on Rheological Measurements}

The linear viscoelastic properties of bitumen can be characterized by applying sinusoidal tests using dynamic testing by applying oscillating shear strain and shear stresses to a bitumen specimen under different temperature and frequency. In this research, Amplitude Sweep Test (AST), Frequency Sweep Test (FST), Performance Grade determination (PG) and Multiple Stress Creep Recovery Test (MSCR) were conducted to characterize the viscoelastic properties of the bitumen. Amplitude Sweep analysis was conducted using three temperatures $\left(21.1^{\circ} \mathrm{C}, 37.8^{\circ} \mathrm{C}\right.$ and $\left.54.4^{\circ} \mathrm{C}\right)$ over a constant frequency of $1.59 \mathrm{~Hz}$.

Frequency Sweep analysis was conducted using three temperatures $\left(21.1^{\circ} \mathrm{C}\right.$, $37.8^{\circ} \mathrm{C}$ and $\left.54.4^{\circ} \mathrm{C}\right)$ over wide frequency ranges $(0.1 \mathrm{~Hz}$ to $25 \mathrm{~Hz})$. The $8 \mathrm{~mm}$ plate configuration with $2 \mathrm{~mm}$ gap setting was used for testing at $21.1^{\circ} \mathrm{C}, 37.8^{\circ} \mathrm{C}$ while $54.4^{\circ} \mathrm{C}$ test temperatures were tested using the $25 \mathrm{~mm}$ diameter plate with $1 \mathrm{~mm}$ gap setting. Before testing, the bitumen specimens were conditioned using the Rolling Thin Film Oven (RTFO). This short-term aging process simulates the hardening that occurs during the mixing and compaction of asphalt mixtures. The result of FST were interpreted from developed complex modulus master curve in one plot based on William-Landel-Ferry (WLF) functions, to express temperature shift factor, $\mathrm{a}(\mathrm{T})$, as selected reference temperature for bitumen ( see Figure 6a and $b$ ).

Both performance grade and multiple stress creep recovery were conducted using $25 \mathrm{~mm}$ diameter plate with $1 \mathrm{~mm}$ gap setting. The performance grade of bitumen was evaluated using the AASHTO M320 specification. A series of MSCR test were performed on aged binder PG temperature to evaluate the creep recovery (elastic) properties of bitumen by $1 \mathrm{sec}$ load and $9 \mathrm{sec}$ rest period principles at $0.1 \mathrm{kpa}$ stress for 10 cycles and increased to $3.2 \mathrm{kpa}$ for $10 \mathrm{cycles}$. At the end of each cycle the creep and recovery strain were computed as explained equations in AASHTO T 350. 


\section{Result and Discussions}

\section{Amplitude Sweep Test Results}

In order to compare and discuss the linearity of bitumen results, different factors are considered because temperature, content of modifiers, and aging, as is shown in Table 3 and 4 . Figure 4 and 5 were made as an example to represent $3 \%$ modified aged and unaged bitumen respectively.

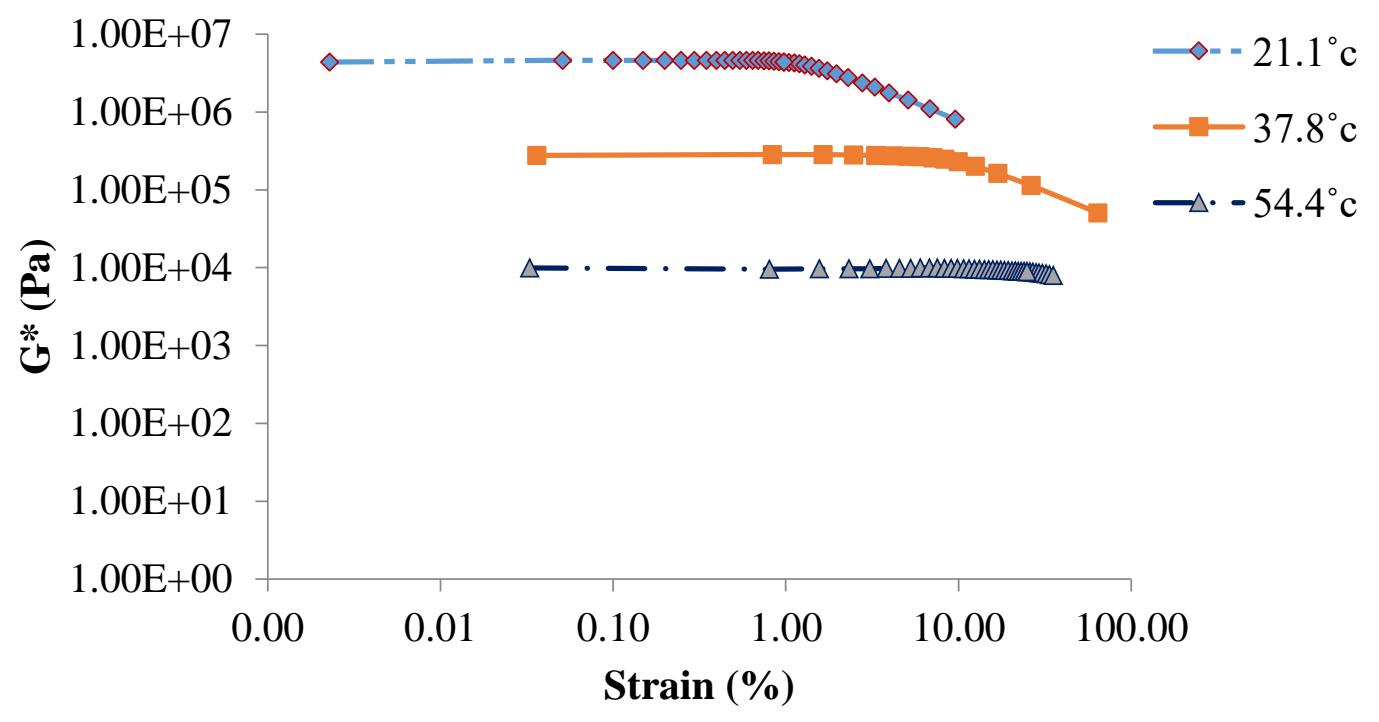

Figure 4. Linear Visco-Elastic range for 3\% modified aged binder

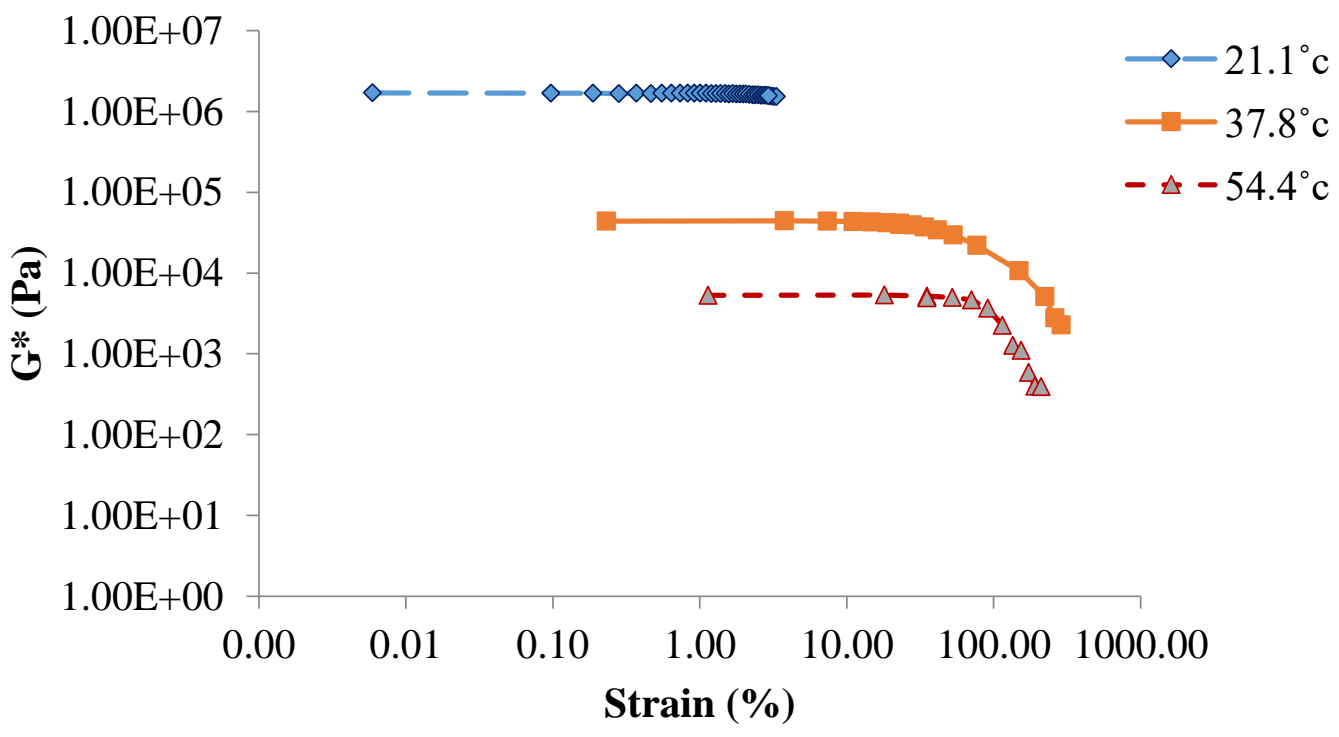

Figure 5. Linear Visco-Elastic range for 3\% modified un-aged binder

Generally, table below shows as temperature increases result in decrease in the values of complex modulus $\mathrm{G}^{*}$ and increases the values of strain. In all aged and un-aged asphalt, mastics analyzed herein the use of modifier increases, stiffness of bitumen increase at high temperature $54.4^{\circ} \mathrm{C}$. Additionally, aging increases the values complex modulus and decreases strain value of bitumen that indicates the hardening of bitumen minimize the permanent deformation. 
Table 3. The Summary of Limiting Strain of Modified Aged Binder

\begin{tabular}{lllll}
\hline Temperature & Modified \% & Peak & $\mathbf{0 . 9 5} * \mathbf{G}$ & Limiting Strain \\
\hline \multirow{2}{*}{$21.1^{\circ} \mathrm{C}$} & $0 \%$ & $1.65 \mathrm{E}+06$ & $1.56 \mathrm{E}+06$ & 2.93 \\
& $1 \%$ & $4.00 \mathrm{E}+06$ & $3.80 \mathrm{E}+06$ & 2.06 \\
& $2 \%$ & $4.60 \mathrm{E}+06$ & $4.37 \mathrm{E}+06$ & 1.96 \\
& $3 \%$ & $1.50 \mathrm{E}+06$ & $1.42 \mathrm{E}+06$ & 1.03 \\
$37.8^{\circ} \mathrm{C}$ & $0 \%$ & $4.11 \mathrm{E}+04$ & $3.91 \mathrm{E}+04$ & 27.85 \\
& $1 \%$ & $2.53 \mathrm{E}+06$ & $2.40 \mathrm{E}+06$ & 7.08 \\
& $2 \%$ & $2.70 \mathrm{E}+05$ & $2.57 \mathrm{E}+05$ & 3.93 \\
& $3 \%$ & $4.70 \mathrm{E}+05$ & $4.47 \mathrm{E}+05$ & 1.94 \\
$54.4^{\circ} \mathrm{C}$ & $0 \%$ & $5.31 \mathrm{E}+03$ & $5.04 \mathrm{E}+03$ & 35.00 \\
& $1 \%$ & $9.40 \mathrm{E}+03$ & $8.93 \mathrm{E}+03$ & 25.38 \\
& $2 \%$ & $1.29 \mathrm{E}+04$ & $1.23 \mathrm{E}+04$ & 24.93 \\
& $3 \%$ & $1.37 \mathrm{E}+04$ & $1.30 \mathrm{E}+04$ & 16.15
\end{tabular}

Table 4. The Summary of Limiting Strain of Modified Un-aged Binder

\begin{tabular}{lllll}
\hline Temperature & Modified \% & Peak & $\mathbf{0 . 9 5 * G}$ & $\begin{array}{c}\text { Limiting } \\
\text { Strain }\end{array}$ \\
\hline \multirow{3}{*}{$21.1^{\circ} \mathrm{C}$} & $0 \%$ & $7.70 \mathrm{E}+05$ & $7.31 \mathrm{E}+05$ & 1.89 \\
& $1 \%$ & $3.21 \mathrm{E}+06$ & $3.05 \mathrm{E}+06$ & 1.83 \\
& $2 \%$ & $2.90 \mathrm{E}+06$ & $2.76 \mathrm{E}+06$ & 1.81 \\
& $3 \%$ & $1.65 \mathrm{E}+06$ & $1.56 \mathrm{E}+06$ & 2.93 \\
$37.8^{\circ} \mathrm{C}$ & $0 \%$ & $4.34 \mathrm{E}+04$ & $4.12 \mathrm{E}+04$ & 23.00 \\
& $1 \%$ & $1.26 \mathrm{E}+06$ & $1.20 \mathrm{E}+06$ & 8.21 \\
& $2 \%$ & $2.54 \mathrm{E}+05$ & $2.41 \mathrm{E}+05$ & 6.39 \\
$54.4^{\circ} \mathrm{C}$ & $3 \%$ & $4.21 \mathrm{E}+04$ & $4.00 \mathrm{E}+04$ & 23.00 \\
& $0 \%$ & $3.04 \mathrm{E}+03$ & $2.89 \mathrm{E}+03$ & 92.48 \\
& $1 \%$ & $3.88 \mathrm{E}+03$ & $3.69 \mathrm{E}+03$ & 83.80 \\
& $2 \%$ & $4.12 \mathrm{E}+03$ & $3.91 \mathrm{E}+03$ & 40.48 \\
& $3 \%$ & $5.19 \mathrm{E}+03$ & $4.93 \mathrm{E}+03$ & 35.00 \\
\hline
\end{tabular}

\section{Frequency Sweep Test Result}

As observed in Figure $6 \mathrm{a}$ and $6 \mathrm{~b}$ below, the shear modulus behaves because of temperature, the content of modifier, frequency and aging. These can be interpreted as follows; at high temperature and reduced frequency decreases, the shear deformation increases with increasing CBR \% continuously which the increases in resistance to shear deformation which in turn results in an increase in elasticity or ability to store energy. This illustrates that the soften bitumen drops seriously with viscoelastic solid behavior when tested at high temperature and low frequency ranges.

Moreover, at lower temperature and higher reduced frequency, asphalt binder exhibited higher stiffness with different $\mathrm{G}^{*}$ value added to un-aged binder. This indicates that effect of the modifier makes no difference frequency more than $100 \mathrm{~Hz}$. The other important observations from the Figure 6 is the influences of \% CBR added into binder on $\mathrm{G}^{*}$ seems to be not proportional to the $\%$ added, for $2 \%$ modified binder were remains softer before and after ageing that reflects non susceptibility of bitumen for hardening. 


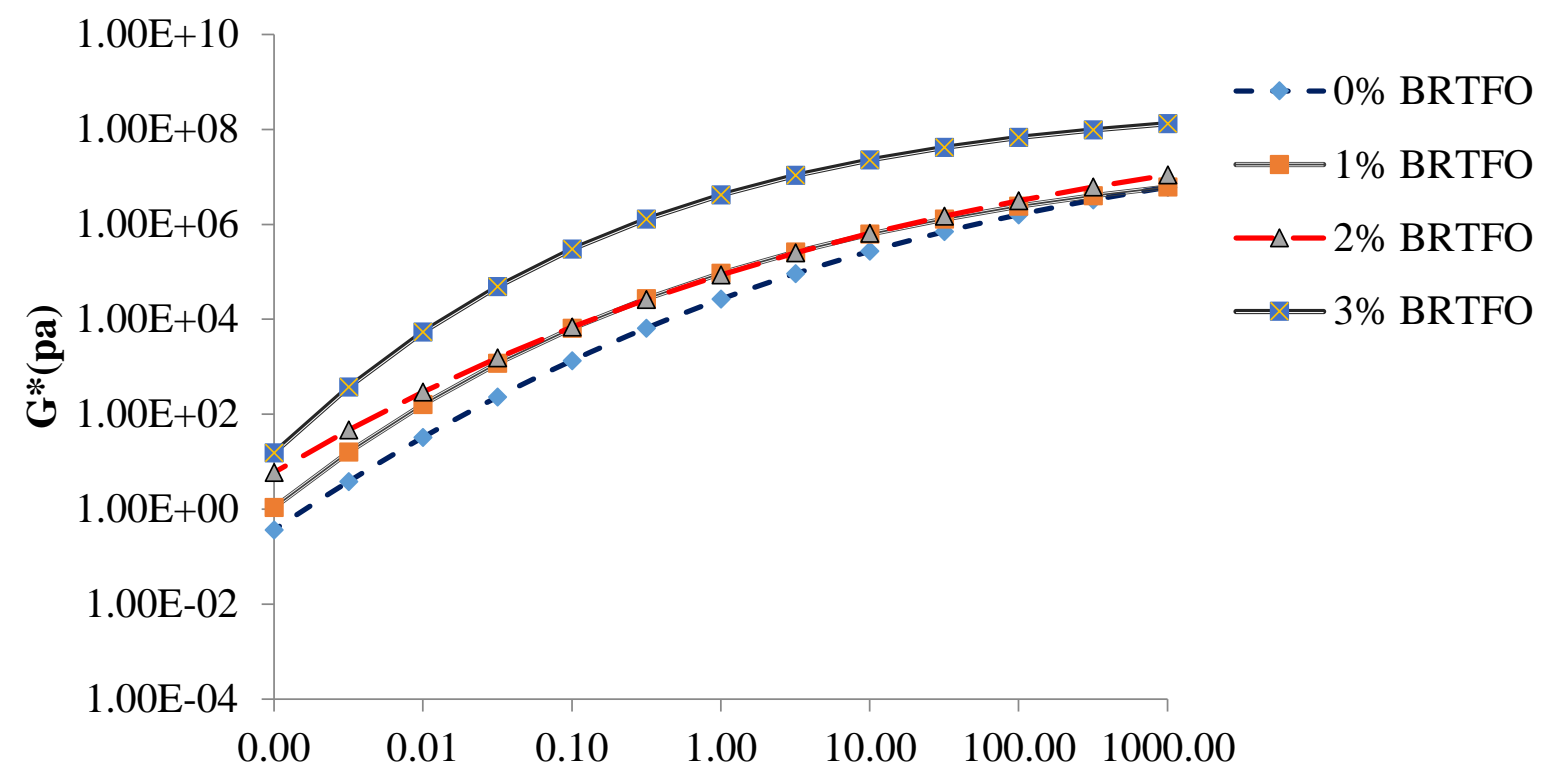

Reduced frequency $(\mathrm{Hz}), 21.1^{\circ} \mathrm{c}$

a)

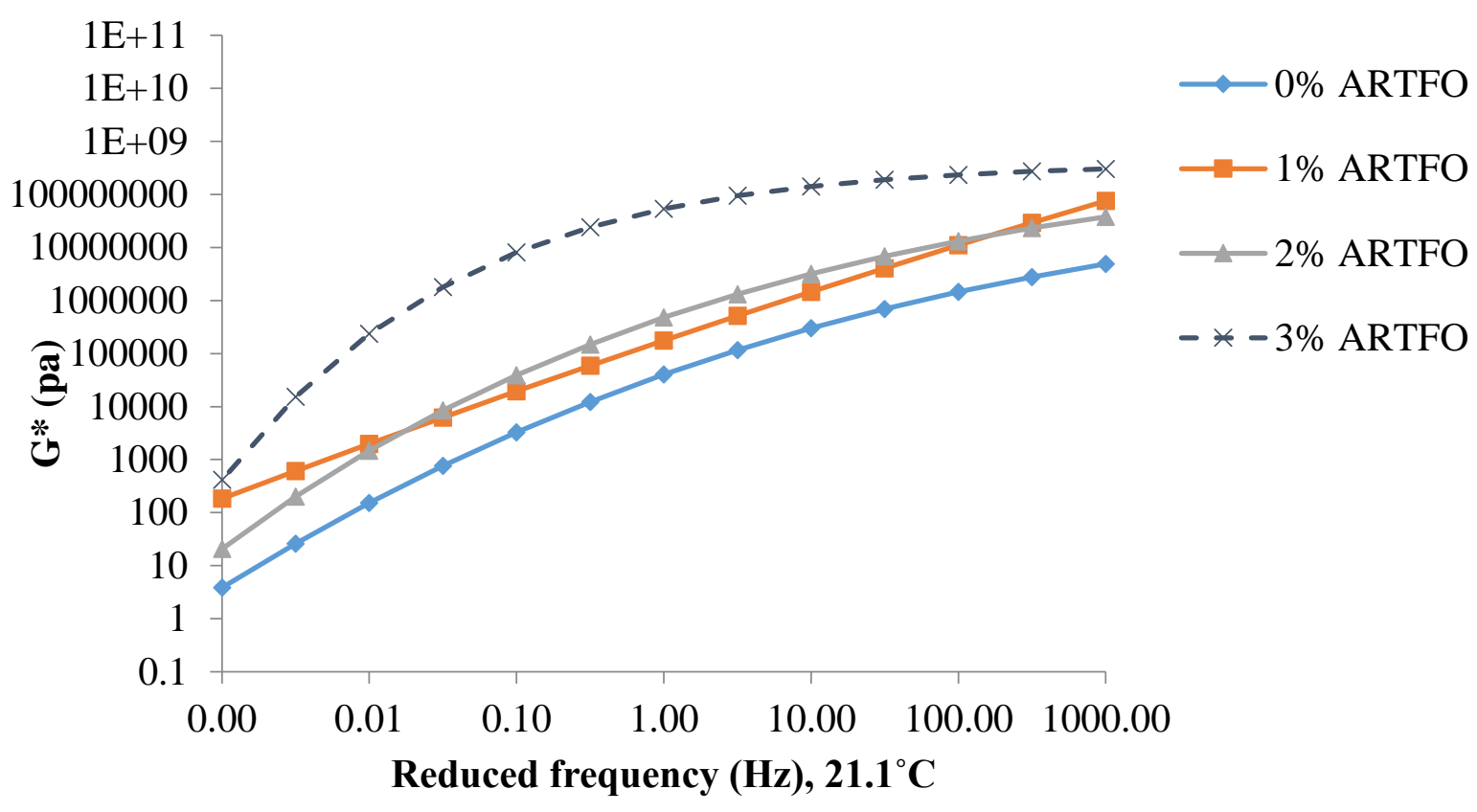

b)

Figure 6. Complex modulus master curve: a) Before rolling thin film oven (BRTFO)

Modified Binder and b) After rolling thin film oven (ARTFO) modified binder

\section{Performance Grade Determination Test Result}

From Table 5 shown below, the rutting parameter $\mathrm{G}^{*} / \sin (\boldsymbol{\delta})$ results obtained from DSR measurements were increased with increasing of CBR, while they are declined significantly with increased temperatures which illustrates that the asphalt binder has improved resistance to rutting and elastic properties. This improvement shows that CBRs modified bitumen may be suitable for using in hot climates to develop stiff flexible asphalt mixtures. 
Table 5. Determined High Temperature Performance Grade (AASHTO-M320)

\begin{tabular}{|c|c|c|c|}
\hline $\begin{array}{l}\text { Modified } \\
\text { Sample }\end{array}$ & $\begin{array}{c}\text { Maximum Temperature } \\
\left({ }^{\circ} \mathrm{c}\right), \mathrm{G} * / \sin \delta \geq 1.0 \mathrm{kpa} \text { Pure } \\
\text { Binder }\end{array}$ & $\begin{array}{c}\text { Maximum } \\
\text { Temperature }\left({ }^{\circ} \mathrm{c}\right), \\
\mathbf{G}^{*} / \sin \delta \geq 2.2 \mathrm{kpa} \text { Aged } \\
\text { Binder }\end{array}$ & PG \\
\hline $0 \%$ & 58 & 58 & PG 58-xx \\
\hline $1 \%$ & 58 & 70 & PG 58-Xx \\
\hline $2 \%$ & 64 & 70 & PG 64-Xx \\
\hline $3 \%$ & 70 & 70 & PG 70-Xx \\
\hline
\end{tabular}

\section{Multiple Stress Creep Recovery Test Result}

Figure 7 and 8 show the graph of creep and recovery percentage for pure and asphalt mastics with the temperature and content of modifiers, for all determination of performance grade after short-term aging. The main purpose of MSCR test is to predict rutting based on response of bitumen to stress and help us to understand the practical information regarding bitumen.

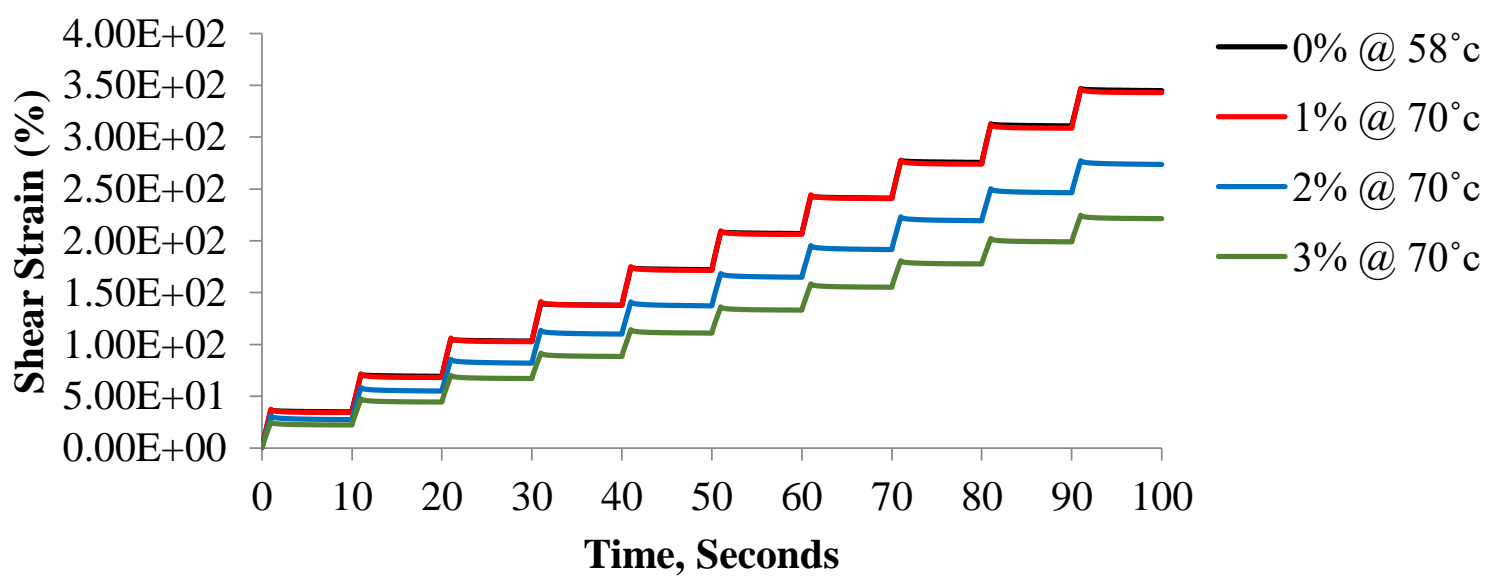

Figure 7 . The effects of ceramic-butyl rubber and temperature on strain $0.1 \mathrm{kpa}$

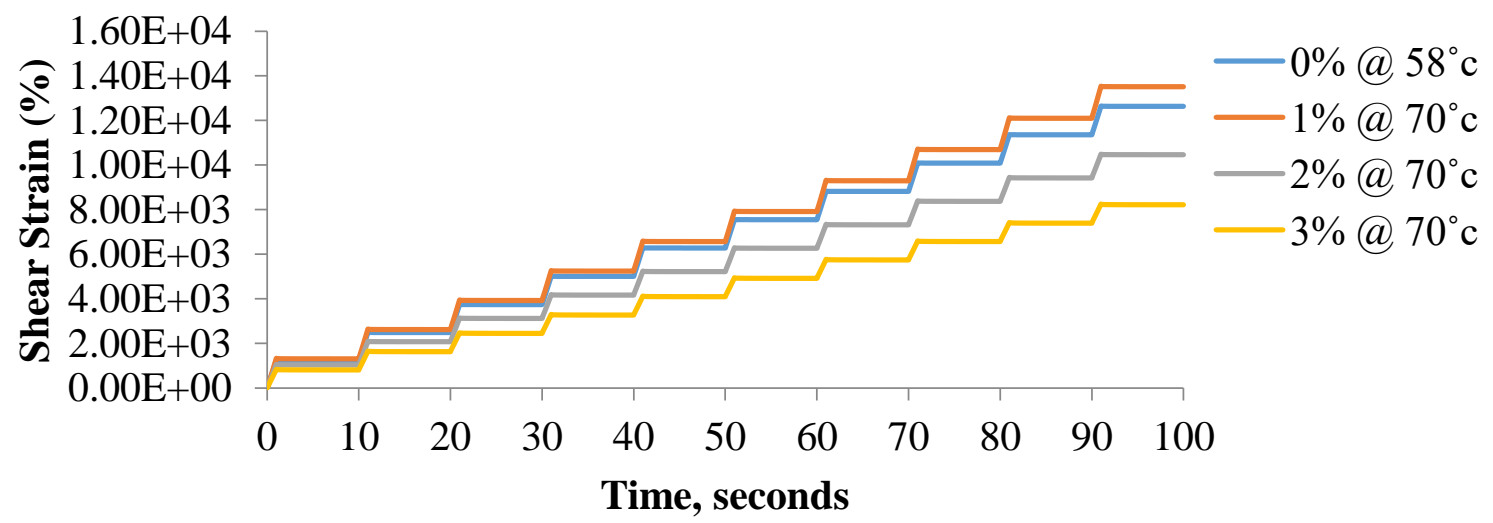

Figure 8. The effects of ceramic-butyl rubber and temperature on strain Jnr3.2 kpa

From the output MSCR, test rutting parameter (Jnr) and percent of recovery (\%R) at $0.1 \mathrm{kpa}$ and $3.2 \mathrm{kpa}$ each specified stress level were determined and summarized in Table 6. The lower value of Jnr is related to rutting. Moreover, as observed from the table rutting 
parameter, $\left(\mathrm{Jnr}_{3.2 \mathrm{kpa}}\right)$ decreases as the CBR modifiers increases at constant temperature except $58^{\circ} \mathrm{C}$. This represents the addition of modifiers could improve flexible pavement rutting distress at $70^{\circ} \mathrm{C}$ and below.

Table 6. Summaries of Analyzed Jnr and \% R for All Neat and Modified Binder

\begin{tabular}{lllll}
\hline Modified, \% & $\mathbf{0 \%}$ & $\mathbf{1 \%}$ & $\mathbf{2 \%}$ & $\mathbf{3 \%}$ \\
\hline Temperature ${ }^{\circ} \mathrm{C}$ & 58 & 70 & 70 & 70 \\
\% Recovery at 0.1kpa & 5.32 & 9.96 & 12.19 & 12.77 \\
\% Recovery at 3.2kpa & 0.79 & 1.68 & 2.33 & 3.46 \\
\% Recovery difference & 85.10 & 83.10 & 80.93 & 72.94 \\
Jnr at 0.1kpa & 3.38 & 3.32 & 2.66 & 2.15 \\
Jnr at 3.2kpa & 3.88 & 4.14 & 3.20 & 2.51 \\
Jnr difference, \% & 14.74 & 24.83 & 20.09 & 16.67 \\
\hline
\end{tabular}

As per of AASHTO MP19 the requirements that difference in Jnr values between $0.1 \mathrm{kpa}$ and $3.2 \mathrm{kpa}$ to reduce asphalt binder sensitive to stress should not exceed $75 \%$ and the difference in percent of recovery must be greater than $25 \%$ or $35 \%$ depend up on traffic volume. Therefore, Figure 9 shows the content of modifier satisfies the criterion given for difference in percent of recovery and the limited value for percent difference in nonrecoverable compliance $\left(J_{\text {nrdiff }}\right)$ between $0.1 \mathrm{kpa}$ and $3.2 \mathrm{kpa}$ were below the limit. As per of AASHTO M 332 comparison made with computed Jnr 3.2kpa, depend on traffic level, load rate, 3\% modified bitumen with CBR shows lower Jnr values in Figure 10 and higher \%R in Figure 11 that indicated stiff binder and improve elastic performance. This represents modifiers improves resistance permanent deformation.

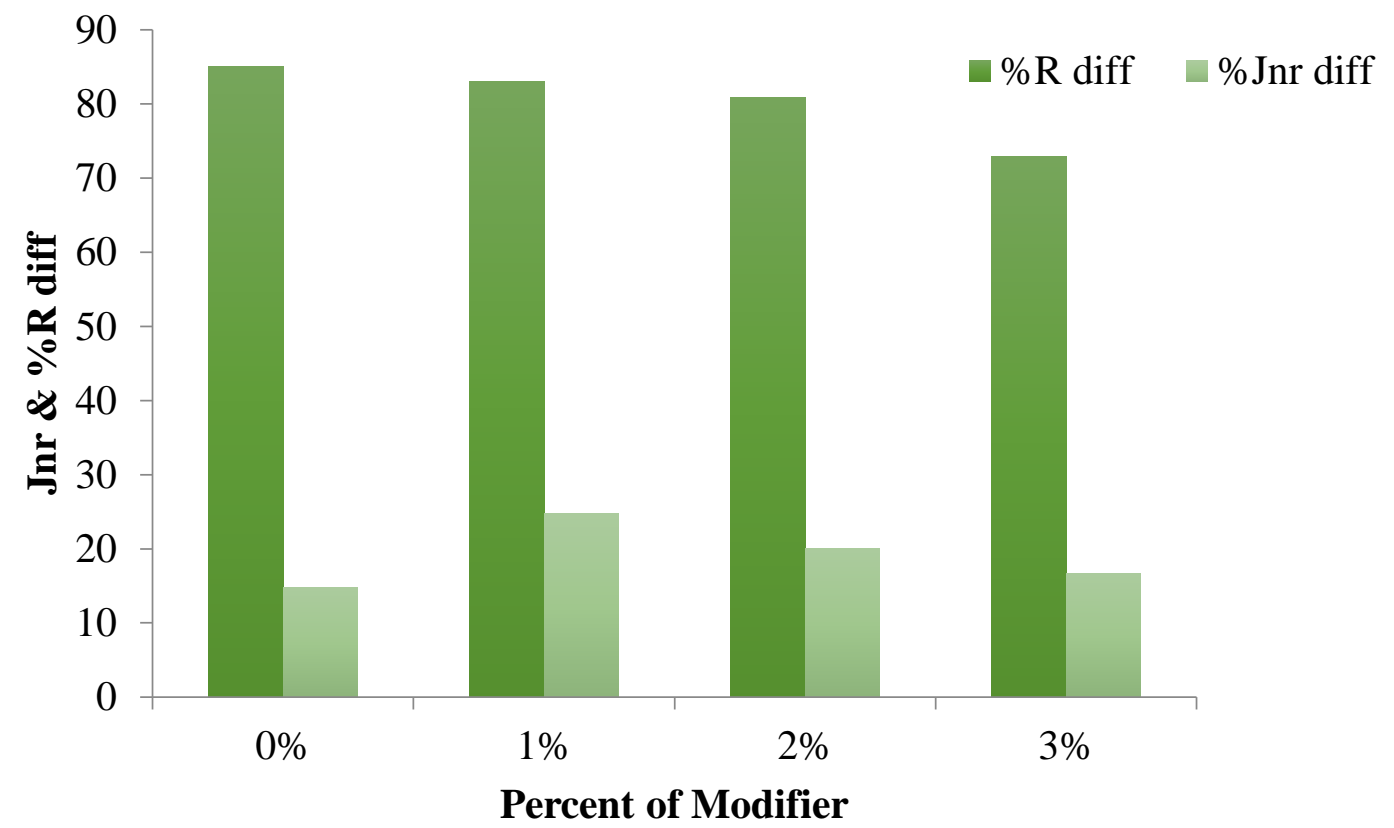

Figure 9. Percentage of recovery and non-recovery compliance difference of aged modified bitumen 


\section{Conclusions and Future Works}

In this research, the physical properties of original and modified asphalt binder with ceramic dust and butyl rubber were conducted and analyzed. Furthermore, the rheological properties of asphalt binders regarding mastics were also assessed. On account of the research results that were discussed above, the following items can be drawn; the ceramic-butyl rubber modified asphalt binder has decreased penetration value, increased softening point and lower ductility value. This indicates that, with the addition of ceramic-butyl rubber modifiers, the stiffness of the bitumen gets up seriously. On the one side, it elaborates that the powders have a great effect on reinforcement of the bitumen so that the asphalt can only undertake less strain under the same stress level. One the other side, the heat insulation effect of the ceramic dust will improve the temperature susceptibility of the asphalt binder. The rheological properties of the bitumen were significantly improved via addition CBR. Additionally, the complex modulus of master curves results illustrates that the addition of ceramic-butyl rubber (CBR) modifiers can enhance the rutting resistance of softer binder at high temperature and low frequency such as $80 / 100$ penetration grade of the bitumen. Moreover, the rutting parameter $\mathrm{G}^{*} / \mathrm{sin}(\boldsymbol{\delta})$ results obtained from DSR measurements were increased from PG $64^{\circ} \mathrm{C}$ to $\mathrm{PG} 70^{\circ} \mathrm{C}$ with increasing of CBR from $2 \%$ to $3 \%$ respectively, while they are declined significantly with increased temperatures. This improvement shows that CBRs modified bitumen may be suitable for using in hot climates to develop stiff flexible asphalt mixtures. Finally, the MSCR test results illustrates that the CBR dramatically increases the resistance of asphalt binder to rutting by reducing the Jnr and increasing the recovery percent of bitumen. Therefore, in this study, resistances to permanent deformation and elastic properties of asphalt binder were enhanced by 3\% CBR modified asphalt binder. Additional assessments are required to investigate rutting performances of asphalt concrete or mixture will be studied in the future work.

\section{Acknowledgements}

The department of civil engineering, college of Architecture and civil engineering of Addis Ababa Science and Technology University, Oda Bultum University has supported this research, and I would like to acknowledge all my family for their unlimited support during my study.

\section{References}

[1] E. Sidding, P. Cheng, and Y. Li, "Effects of polymer modified nanoclay on the performance of asphalt mixture," Magazine of Civil Engineering, Vol. 7, No. 91, pp. 98111, 2019. doi: 10.18720/MCE.91.9.

[2] M. Hasaninia, and F. Haddadi, "The characteristics of hot mixed asphalt modified by nanosilica," Petroleum Science and Technology, Vol. 4, No. 35, pp. 351-359, 2017. doi: 10.1080/10916466.2016.1258412.

[3] Z.A. Alkaissi, "Effect of high temperature and traffic loading on rutting performance of flexible pavement," Journal of King Saud University - Engineering Sciences, Vol. 1, No. 32, pp. 1-4, 2020. doi: 10.1016/j.jksues.2018.04.005.

[4] A.K. Das, and M. Panda, "Investigation on rheological performance of sulphur modified bitumen (SMB) binders," Construction and Building Materials, Vol. 149, pp. 724-732, 2017. doi: 10.1016/j.conbuildmat.2017.05.198.

[5] C. Li, Z. Chen, S. Wu, B. Li, J. Xie, and Y. Xiao, "Effects of steel slag fillers on the rheological properties of asphalt mastic," Construction and Building Materials, Vol. 145, pp. 383-391, 2017. doi:1 0.1016/j.conbuildmat.2017.04.034.

[6] D.A. Gama, J.M. Rosa, T.J.A. De Melo, and J.K.G. Rodrigues, "Rheological studies of 
asphalt modified with elastomeric polymer," Construction and Building Materials, Vol. 106, pp. 290-295, 2016. doi: 10.1016/j.conbuildmat.2015.12.142.

[7] M. Anderson, and J. Bukoski, Using the Multiple Stress Creep Recovery, North Central Asphalt User Producer Group Meeting, Indianapolis, Indiana, 2012..

[8] D.I. Alhamali, J. Wu, Q. Liu, N.A. Hassan, N.I.M. Yusoff, and S.I.A. Ali, "Physical and rheological characteristics of polymer modified bitumen with nanosilica particles," Arabian Journal for Science and Engineering, Vol. 41, No. 4, pp. 1521-1530, 2016. doi: 10.1007/s13369-015-1964-7.

[9] U. Isacsson, and X. Lu, "Testing and appraisal of polymer modified road bitumens-state of the art," Materials and Structures, Vol. 28, No. 3, pp. 139-159, 1995. doi: 10.1007/BF02473221.

[10] Asphalt Academy, Use of Modified Bituminous Binders in Road Construction: Technique Guide, $3^{\text {rd }}$ Edition [Online]. Avalaible: https://www.asphaltacademy.co.za/wp-content/uploads/2016/09/TG1-2015_web.pdf [Accessed: July 2015]

[11]F. Cardone, F. Frigio, G. Ferrotti, and F. Canestrari, "Influence of mineral fillers on the rheological response of polymer-modified bitumens and mastics," Journal of Traffic and Transportation Engineering (English Edition), Vol. 2, No. 6, pp. 373-381, 2015. doi: 10.1016/j.jtte.2015.06.003.

[12] S.E. Zoorob, J.P. Castro-Gomes, L.A. Pereira Oliveira, and J.O. Connell, "Investigating the multiple stress creep recovery bitumen characterisation test," Construction and Building Materials, Vol. 30, pp. 734-745, 2012. doi: 10.1016/j.conbuildmat.2011.12.060.

[13]G. Liu, T. Yang, J. Li, Y. Jia, Y. Zhao, and J. Zhang, "Effects of aging on rheological properties of asphalt materials and asphalt-filler interaction ability," Construction and Building Materials, Vol. 168, pp. 501-511, 2018. doi: 10.1016/j.conbuildmat.2018.02.171.

[14]D. Feng, J. Yi, and D. Wang, "Performance and thermal evaluation of incorporating waste ceramic aggregates in wearing layer of asphalt pavement," Journal of Materials in Civil Engineering, Vol. 25, No. 7, pp. 857-863, 2013. doi: 10.1061/(ASCE)MT.19435533.0000788.

[15] Y. Dui, S. Qin, and S. Wang, "Bidirectional heat induced structure of asphalt pavement for reducing pavement temperature," Journal of Applied Thermal Engineering, Vol. 75, pp. 298-306, 2015. doi: 10.1016/j.applthermaleng.2014.10.011.

[16]E. Fatima, S. Sahu, A. Jhamb, and R. Kumar, "Use of ceramic waste as filler in semidense bituminous concrete, American Journal of Civil Engineering and Architecture, Vol. 2, No. 3. pp. 102-106, 2014. doi: 10.12691/ajcea-2-3-2.

[17]J. Wan, S. Wu, Y. Xiao, Q. Liu, and E. Schlangen, "Characteristics of ceramic fiber modified asphalt mortar," Materials, Vol. 9, No. 9, pp. 1-12, 2016. doi: 10.3390/ma9090788.

[18]S. Mostafa, M.W.Hussin, L. Han-seung and M.S Abdul Rahman, "Properties of mortar containing ceramic powder waste as cement replacement"Jurnal Teknologi, Vol. 77, No. 12, pp. 27-32, 2016. DOI: 10.11113/jt.v77.63155

[19] E.A. Abdelzaher, A.M. Nasser, M. Abdel-Fattah, Abd El-Wahab and G. Ahmed, "Improving of reclaimed asphalt pavements using styrene-butyl acrylate polymer," Global Journal of Engineering Science and Researches, Vol. 4, No. 9, pp. 2323-2334, 2017, doi: 10.5281/zenodo.929107.

[20]A. Khadivar, and A. Kavussi, "Rheological characteristics of SBR and NR polymer modified bitumen emulsions at average pavement temperatures," Construction and Building Materials, Vol. 47, pp. 1099-1105, 2013. doi: 
10.1016/j.conbuildmat.2013.05.093.

[21] Annual Book of ASTM Standards, Standard Test Method for Penetration of Bituminous Materials: Manual on Hydrocarbon Analysis, $6^{\text {th }}$ Edition, pp. 1-4, West Conshohocken, United states, 2008.

[22] Annual Book of ASTM Standards, Standard Test Method for Softening Point of Bitumen: Manual on Hydrocarbon Analysis, $6^{\text {th }}$ Edition, West Conshohocken, United states, pp. 1-5, 2008.

[23] Annual Book of ASTM Standards, Standard Test Method for Effect of Heat and Air on a Moving Film of Asphalt (Rolling Thin-Film Oven Test), West Conshohocken, United states, pp. 1-6, 2004.

[24] Annual Book of ASTM Standards, Ductility of Bituminous Materials (ASTM-D113). West Conshohocken, United states, pp. 1-5, 2007. doi:10.1520/D0113-07.2,

[25]K. Zahra, Properties of Bituminous Mix and Binder Modified with Waste Polyethylene Terephthalate, Thesis (Master's), University of Malaya, 2012.

[26]F. Moreno, and M.C. Rubio, "Analysis of digestion time and the crumb rubber percentage in dry-process crumb rubber modified hot bituminous mixes," Construction and Building Materials, Vol. 25, No. 5, pp. 2323-2334, 2011. doi:10.1016/j.conbuildmat.2010.11.029 